\title{
ARTICLE
}

\section{Density and Survival of Walleye Eggs and Larvae in a Great Lakes Tributary}

\section{E. S. Rutherford*}

National Oceanic and Atmospheric Administration, Great Lakes Environmental Research Laboratory, 4840 South State Road,Ann Arbor, Michigan 48118, USA

\section{J. Allison}

Pennsylvania Fish and Boat Commission, 450 Robinson Lane, Bellefonte, Pennsylvania 16823, USA

\section{R. Ruetz III}

Annis Water Resources Institute, Grand Valley State University, 740 West Shoreline Drive, Muskegon, Michigan 49441, USA

\section{J. R. Elliott}

National Oceanic and Atmospheric Administration, Great Lakes Environmental Research Laboratory, Lake Michigan Field Station, 1431 Beach Road, Muskegon, Michigan 49441, USA

\section{J. K. Nohner}

Center for Systems Integration and Sustainability, Michigan State University, 115 Manly Miles Building, 1405 South Harrison Road, East Lansing, Michigan 48823, USA

\section{R. DuFour}

Lake Erie Center, Department of Environmental Sciences, University of Toledo, 6200 Bayshore Road, Oregon, Ohio 43616, USA

\section{R. P. O'Neal}

Michigan Department of Natural Resources, 7550 East Messinger Road, Twin Lake, Michigan 49457, USA

\section{J. Jude}

School of Natural Resources and Environment, University of Michigan, 440 Church Street, Ann Arbor, Michigan 48109, USA

\section{S. R. Hensler}

Detroit River International Wildlife Refuge, Large Lakes Research Station, 9311 Groh Road, Grosse Ile, Michigan 48138, USA

\footnotetext{
Abstract

The Walleye Sander vitreus is an important sport fish that has experienced low reproductive success in some Great Lakes tributaries since severe population declines began in the late 1940s. In the Muskegon River, a Lake Michigan tributary, natural reproduction of Walleyes remains low and is largely supplemented by stocking. We evaluated the influence of abiotic factors on Walleye reproductive success in the Muskegon River during April and
}

*Corresponding author: edwardr@umich.edu

Received February 9, 2015; accepted January 11, 2016 
May 2009 and 2010 by (1) estimating Walleye egg density and survival; (2) estimating the size, density, abundance, and survival of Walleye larvae; and (3) relating our estimates to physical habitat conditions. Egg densities were 70fold higher in 2009 than in 2010, but eggs experienced colder water temperatures, higher river discharge rates, and lower survival in 2009 relative to 2010 . Egg survival in incubators was positively related to temperature and negatively related to flow at most sites. In both years, Walleye larvae that hatched during periods of cooler temperature were smaller than larvae that hatched later during periods of warmer temperature. Walleye larval densities were highest near spawning grounds and decreased downstream. Bayesian estimates of variability in larval densities indicated that temporal variability was twice as high as spatial variability in the Muskegon River. Larval survival was much lower in 2009 than in 2010, resulting in an approximately sevenfold higher production of larvae in 2010 than in 2009. Survival was highest for smaller larvae that hatched early in April 2010, when temperatures were warm and discharges were low and stable; in contrast, survival was much lower for larger larvae hatching later in 2010 or for large and small larvae in 2009, when water temperatures were colder and discharges were higher and more variable. Our results suggest that abiotic factors, primarily temperature and river flow, likely control the early survival of Walleyes in the Muskegon River.

The Walleye Sander vitreus is a key predator in nearshore food webs and supports valuable commercial and recreational fisheries in the Great Lakes region. Walleye populations were self-sustaining in many tributaries and nearshore areas of the Great Lakes until the 1950s, when the cumulative impacts of dam construction, habitat degradation, mercury contamination, and a likely increase in predation on early life stages lowered their abundance and harvest (Schneider and Leach 1979; Fielder et al. 2007). Walleye reproductive success and potential recruitment are known to be influenced by biotic and abiotic factors occurring during the egg and larval stages. Abiotic factors - primarily river flow and temperature-are known to affect the production and survival of Walleye eggs and larvae, with higher discharges and colder temperatures decreasing egg and larval survival and abundances (Mion et al. 1998; Ivan et al. 2010; Crane and Farrell 2013; DuFour et al. 2014; Raabe and Bozek 2015). Cold water temperatures can delay egg development and can reduce survival through increased exposure to predation or disease. Biotic factors, especially predation on eggs and larvae (Corbett and Fowles 1986; Roseman et al. 2006; Fielder et al. 2007), also have been suggested as influencing Walleye reproductive success.

The Muskegon River, a tributary to Lake Michigan, historically supported one of the largest adfluvial Walleye runs in the lake, but a population decline starting in the late 1940s lowered Walleye abundances from over 120,000 adults to fewer than 7,000 adults by the late 1960s (Schneider and Leach 1979). Walleye spawning in the Muskegon River was altered by construction of the Newaygo Dam (Figure 1) in 1910, which blocked the upstream movement of fish and reduced the amount of available spawning habitat (Schneider and Leach 1979). The Newaygo Dam subsequently collapsed and was removed by floods in 1968, allowing Walleyes to access spawning grounds upriver. Starting in 1978, an aggressive stocking program of 50,000 juveniles/year has rebuilt the adult population to over 40,000 individuals (Hanchin et al. 2007 ), but presently only $5-10 \%$ of the population is sustained through natural reproduction (O'Neal 1997), suggesting the presence of recruitment bottlenecks in both the Muskegon River and Muskegon Lake.

Factors preventing Walleye reproductive success in the Muskegon River remain unclear. Walleye egg production appears to be substantial and the eggs are viable (Ivan et al. 2010), but larval fish densities sampled in 1986 were low (Day 1991). High river discharge is known to negatively influence Walleye recruitment (Mion et al. 1998), and discharge in the Muskegon River increased 34\% between 1934 and 2001 (estimated from U.S. Geological Survey [USGS] gauging station 04121650 at Big Rapids, Michigan). Cold water temperatures on the spawning grounds, which are associated with upstream hydroelectric dams, also could negatively affect the survival of Walleye eggs and larvae. Through analysis of Walleye harvest data, Schneider et al. (1991) found that strong year-classes in Lake Michigan were produced during years with warm spring temperatures. Although experiments by Schneider et al. (2002) indicated that Walleye eggs are very resilient to fluctuations in temperature, extended periods of cold temperature can delay egg development (Koenst and Smith 1976), thereby increasing the potential for egg predation or for the eggs to be dislodged and advected by floods to unfavorable habitats downstream (Johnson 1961).

Biotic factors like predation can also influence Walleye reproductive success. Predation on Walleye larvae by Alewives Alosa pseudoharengus (Madenjian et al. 2008) was considered a potential factor affecting low recruitment in the Muskegon Lake-Muskegon River system (Day 1991) and in Saginaw Bay, Lake Huron (Fielder et al. 2007). In addition, populations of invasive zebra mussels Dreissena polymorpha have been present in Muskegon River and Muskegon Lake since the late 1990s and have altered the composition of spawning habitat (Giuliano 2011), reducing the interstitial spaces that are critical for the retention of Walleye eggs (Crane and Farrell 2013). Egg incubation experiments and surveys conducted in 2005-2006 by Ivan et al. (2010) indicated that egg survival varied among locations in the Muskegon River but was not related to shear stress, substrate composition, or velocity. Walleye eggs in 


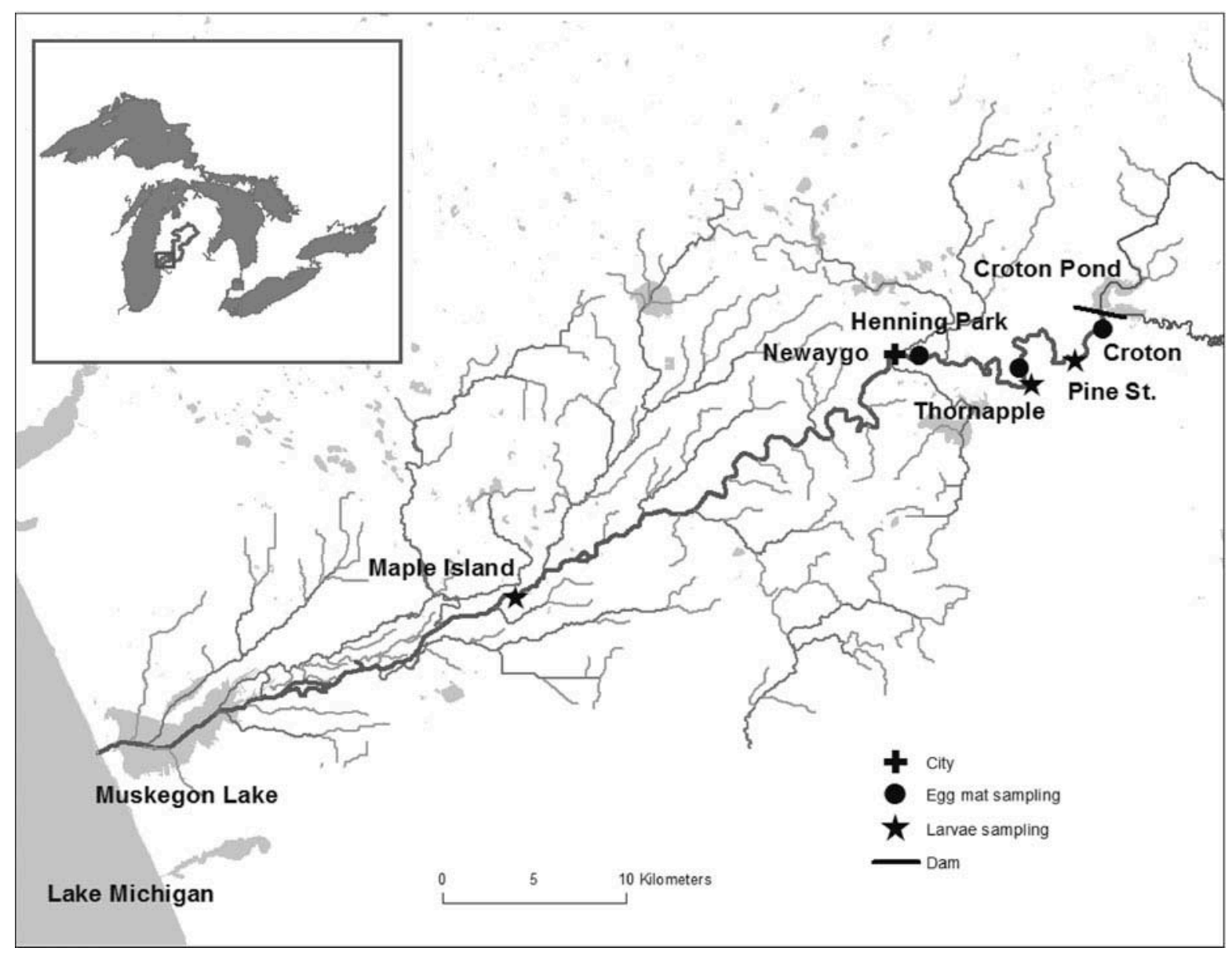

FIGURE 1. Map of the Muskegon River (Michigan), a tributary of Lake Michigan, showing sampling locations that were used to estimate Walleye egg and larval densities. Each egg mat sampling site on the map consists of two locations, resulting in a total of six sites.

covered incubators had higher survival than eggs that were deposited in situ on uncovered furnace mats, indicating that egg predation could be an important determinant of recruitment success (Ivan et al. 2010).

Our goal was to investigate potential bottlenecks to Walleye reproductive success in the lower Muskegon River. Specifically, our objectives were to (1) estimate Walleye egg density and survival in prime spawning areas of the Muskegon River; (2) quantify spatiotemporal variation in Walleye larval density and abundance on spawning grounds and larval survival to downstream areas of the river; and (3) relate variation in egg density, egg survival, and larval survival to environmental variables.

\section{METHODS}

Study site.-The Muskegon River drains about $6,700 \mathrm{~km}^{2}$ in the western central portion of Michigan's Lower Peninsula. The river flows into Muskegon Lake, a drowned river mouth system (Steinman et al. 2008) that is connected to Lake
Michigan via a navigation channel. Since the collapse of Newaygo Dam in 1968, adfluvial Walleyes have spawned primarily below Croton Dam (Figure 1) in areas with rocky substrate, rapid flows $(>1 \mathrm{~m} / \mathrm{s})$, and cold hypolimnetic water from the dam's reservoir upstream (O'Neal 1997). Croton Dam, a hydroelectric facility located at river kilometer 80 , blocks the upstream migration of all fish and alters the temperature and flow of the Muskegon River; the impoundment created by the dam is used for flood control (O’Neal 1997). Our study sites in the Muskegon River were located within a $60-\mathrm{km}$ reach downstream of the dam.

River environment.-Daily measures of Muskegon River water temperature and discharge during April-May 2009 and 2010 were obtained from USGS gauging station 04121970 at Croton Dam (USGS 2011), upstream of the Walleye spawning area (Figure 1). Each time a sample was taken at any site, environmental variables were measured by using a multiprobe sonde (YSI Model 6600v2; Yellow Springs Instruments, Inc.) and a portable flow meter (Marsh-McBirney Flo-Mate Model 2000). Measured variables included water temperature, depth, 
velocity, $\mathrm{pH}$, turbidity, and dissolved oxygen concentration. Paired $t$-tests were used to distinguish differences in river temperature and discharge between years; ANOVA was used to test for differences in other variables among sites and between years.

Substrate composition also was measured at each egg mat site (described below; Figure 1). Three representative surface substrate samples were collected with a 1.9-L scoop within a few meters of each mat at each site on June 25, 2009, and May 3,2010 . Substrate samples were then transported to the laboratory, where they were dried to a constant mass in a desiccating oven at $80^{\circ} \mathrm{C}$. Samples were dry-sieved by using a sieve shaker (CSC Model 18480) and four stacked sieves (64, 16, and $2 \mathrm{~mm}$ along with a collection basin on bottom). After about 5 min of shaking, each grain size category was weighed to the nearest $0.01 \mathrm{~g}$ on a top-loading balance, and the contribution of each category was expressed as a proportion of the total sample.

Collection of spawning females and eggs.-Fertilized eggs for estimating Walleye egg survival in incubators were obtained from Michigan Department of Natural Resources (MDNR) Fisheries Division personnel during their hatchery program's egg take on the Muskegon River (below Croton Dam) on April 2 and 9, 2009, and March 25 and 29, 2010. Adult Walleyes were captured by boat electrofishing, brought to holding pens, measured, and weighed; gametes were then collected on site. Significant differences in mean length or weight of females between years or between collection weeks were tested by using ANOVA; a Wilcoxon rank-sum test was used for the comparison if data did not meet the assumptions of normality and homogeneity of variance. Significant differences were assessed at an $\alpha$ level of 0.05. We used JMP version 10.0.1 to conduct statistical tests. Eggs were fertilized at a male: female ratio of 1:1. Fertilized eggs from five adult pairs were then combined in a bucket containing a bentonite-clay mixture in water to prevent the adhesion of eggs during the 60 -min water hardening process. After water hardening, eggs were rinsed of clay particles and were transferred to a glass tray, where they were pipetted into incubator chambers for in situ survival experiments (described below).

Egg density sampling.-Densities of naturally spawned Walleye eggs in the Muskegon River were estimated using furnace filter mats in accordance with the design described by Manny et al. (2007). Mats consisted of a furnace filter $(60 \times$ $76 \mathrm{~cm})$ that was wrapped around a steel frame $(60 \times 38 \mathrm{~cm})$ and held in place with binder clips. Mats were then grouped together in gangs of three, and an anchor was attached to the upstream end. One gang of mats was deployed at random locations along the river margin at each of six sites (Figure 1) prior to Walleye spawning activity each spring (March 24, 2009; and March 22, 2010). Site locations were stratified across three regions of the river that represented a longitudinal gradient from Croton Dam (Figure 1). Thus, our estimates of egg density on mats should be viewed as indices of egg density in the substrate rather than estimates of true egg abundance in the substrate.

Egg mats were sampled weekly. The surface of each mat was divided into eight equal sections. Each week for six consecutive weeks in 2009 and five consecutive weeks in 2010 , one sample was randomly selected for removal from each mat at all sites. The same mat was then redeployed in the river. A small proportion of the eggs was lost during mat retrieval and redeployment; however, we assumed that the proportion was constant among mats. The selected mat sections were preserved in a $10 \%$ solution of buffered formalin. In the laboratory, each mat section was measured on two sides to the nearest $0.10 \mathrm{~mm}$ by using calipers (mean sample area $=$ $44.65 \mathrm{~cm}^{2}$ in 2009 and $35.1 \mathrm{~cm}^{2}$ in 2010 ), and all eggs were identified and enumerated. Egg density was expressed as the number of eggs per square meter to standardize for the sampling area on the mat.

The majority of eggs were sampled within a 3-week period corresponding to the peak of the Walleye spawning run from late March to mid-April. We calculated the 3-week peak mean egg density (hereafter, "peak mean egg density") by averaging individual mat estimates over the 3 weeks with the greatest egg densities to provide three replicates per site (i.e., a peak mean estimate for mats 1,2 , and 3 at each site). We then used a two-way ANOVA to test whether the peak mean egg density significantly differed among sites or between years; the site $\times$ year interaction was also evaluated. If a significant difference was detected with ANOVA, then Tukey's honestly significant difference (HSD) test was used to identify differences. Residual plots were examined to determine whether transformations were necessary to correct for heteroscedasticity. In both study years, a square-root transformation (plus 1 to account for zeros) was applied to the peak mean egg densities for analysis.

Egg survival on mats.-Walleye egg survival also was quantified by observing the developmental stage of eggs collected on mats. Eggs collected in 2009 and 2010 were cleared by using Stockard's solution via the method of Galat (1972) to allow for observation of embryos. Embryos were examined under a phase-contrast microscope with variable magnification, and the egg developmental stage was determined (Heidinger et al. 1997). Developmental stages were grouped into four categories: deceased, stage 1, stage 2 , or stage 3 . Stage-1 eggs were pre-organogenesis and had not acquired 28 temperature units; stage- 3 eggs were just about to hatch, exhibiting well-developed eyes, caudal mesenchyme, and pectoral fin buds, and had acquired at least 97 temperature units; and stage-2 eggs were intermediate between stages 1 and 3 (Heidinger et al. 1997).

Annual egg survival was estimated for each site in 2009 and 2010. For each year, egg densities were pooled across all three mats at each site. A density-weighted mean date of collection (Ruetz and Jennings 1999) was calculated for the initial number of eggs and for stage-3 eggs as 


$$
D_{i}=\left(\Sigma d_{i} J_{i}\right) /\left(\Sigma d_{i}\right),
$$

for $i=1,2, \ldots, n$, where $d_{i}$ is the density at each sampling event for the initial number of eggs or stage-3 eggs, $J_{i}$ is the Julian date of each sampling event, and $n$ is the number of sampling events. The products of equation (1) for the initial number of eggs $\left(D_{0}\right)$ and for stage- 3 eggs $\left(D_{3}\right)$ were used to estimate the amount of time $(t)$ that was necessary for an average egg collected to achieve stage-3 status. This was done by subtracting the density-weighted mean date of collection for the initial number of eggs from the density-weighted mean date for stage-3 eggs $\left(t=D_{0}-D_{3}\right)$ at each site. The instantaneous mortality rate $(Z)$ was estimated as

$$
Z=\log _{e}\left(N_{t} / N_{0}\right) / t
$$

where $N_{t}$ is the summation of stage- 3 egg densities across all collection dates, $N_{0}$ is the summation of stage- 1 egg densities across all collection dates plus the summation of deceased egg collected during the first two collection dates, and $t$ is the amount of time necessary for an average egg collected to achieve stage-3 status (as described above). Annual egg survival $\left(S_{\text {egg }}\right)$ was then calculated as

$$
S_{\text {egg }}=e^{-Z t}
$$

where $t$ and $Z$ are the products of equation (2).

Egg survival in incubators.-Walleye egg survival in the Muskegon River was quantified by using well incubators via the design described by Manny et al. (1989). Incubator construction consisted of three Plexiglas pieces: a large center piece with 50 wells (well depth $=9.0 \mathrm{~mm}$; diameter $=$ $13.0 \mathrm{~mm}$ ) and two covers containing the same well pattern. Each cover was lined with $400-\mu \mathrm{m}$ Nitex mesh to allow for water exchange. A single egg was placed in each well, and the covers were secured by using thumb screws. After the incubators were inoculated with fertilized eggs, they were grouped together in gangs of three, and an anchor was attached to the upstream end. Incubators were then transported in Muskegon River water to their deployment sites, where they were placed horizontally on the river bottom. Two gangs of incubators were deployed at each site on April 2, 2009, and March 25, 2010 (6 sites $\times 2$ gangs $\times 3$ incubators per gang $=36$ incubators per year); deployments occurred on the same days the eggs were obtained from the MDNR during the Walleye egg take. In each study year, one additional gang of incubators was transported to Thompson State Fish Hatchery (Manistique, Michigan) to serve as a control. Control incubators were maintained at a water temperature of $8.0^{\circ} \mathrm{C}$ for the first $21 \mathrm{~d}$, after which the temperature was increased to $13^{\circ} \mathrm{C}$ until hatch occurred.

In 2009, one gang of incubators was removed from the river at $21 \mathrm{~d}$ postfertilization, and the other gang was removed at $28 \mathrm{~d}$ postfertilization. In 2010 , one gang was removed at $7 \mathrm{~d}$ postfertilization, and the other was removed at $21 \mathrm{~d}$ postfertilization. During sorting, eggs were deemed nonviable if they were completely opaque, contained a white spot, or were completely engulfed in fungus (Johnson 1961). The remaining eggs were deemed viable, and the proportion of eggs surviving the incubation period was calculated.

A two-way ANOVA was used to test whether the proportion of eggs surviving differed between the two incubation periods (i.e., 21 and $28 \mathrm{~d}$ in 2009; 7 and $21 \mathrm{~d}$ in 2010) or among sites within each year; the interaction between incubation period and site was also assessed. The two experiments were analyzed separately because the duration of incubation periods differed between 2009 and 2010. Residual plots were examined to determine whether transformations were necessary to correct for heteroscedasticity; no transformations were needed for data from either year. Two-way ANOVA also was used to test whether the proportion of eggs surviving to $21 \mathrm{~d}$ postfertilization differed between years and among sites and whether the site $x$ year interaction effect was significant. Residual plots provided no evidence for homoscedasticity, so no transformation was used for the data prior to conducting the ANOVA.

Variation in egg density and survival relative to environmental variables.-Spearman's rank correlation coefficients were used to explore relationships between environmental variables and Walleye egg deposition on mats (peak mean egg density) in 2009 and 2010. Environmental variables were represented as the mean and variance (coefficient of variation [CV], \%) of all measurements taken during the duration of a sampling event (22 sampling events per year). Egg survival estimates for mats and incubators (over 21 d) were related to physical habitat variables by using simple linear regression.

Larval drift sampling.-In 2009 and 2010, drift samples were collected to obtain larval Walleyes at three fixed sites in the Muskegon River from early April to mid-May (Figure 1; Supplementary Table S.1 available in the online version of this paper). Sites were located near the Pine Street boat launch (hereafter, "Pine Street"), near the Thornapple boat launch (hereafter, "Thornapple"), and near the B-31 bridge at Maple Island Road (hereafter, "Maple Island Road"). In both years, sampling frequency was increased from 2 nights/week in early April to 4 nights/week during the seasonal peak of larval fish drift in mid- to late April and then was decreased to 2 nights/ week in mid-May.

Drift samples were collected by using paired conical drift nets $(333-\mu \mathrm{m}$ mesh; $0.5-\mathrm{m}$ diameter) with flow meters (Ragosha) attached to the center. In both study years, samples were collected at night, as literature reports suggested that Walleye larval drift is highest at night (Jude 1992; D'Amours et al. 2001). A diel survey of larval drift was also conducted at the Maple Island Road site to confirm that Walleye larval drift was highest at night and to better compare our results with those of a previous study that was conducted 
in the Muskegon River during the daytime (Day 1991). Walleye larvae were collected every $2 \mathrm{~h}$ starting at 1800 hours on April 25 and ending at 1400 hours on April 26. Two replicate stations were established at each site except when conditions limited our access to suitable anchoring locations. Using river anchors and buoys, 10-min surface samples and near-bottom samples were collected at each station, resulting in a total of 4 samples/site. Samples were washed with water into Nitex mesh $(333 \mu \mathrm{m})$ covered containers, concentrated into sample jars, and preserved in a $95 \%$ solution of ethanol for later examination in the laboratory.

Fish larvae were removed from preserved samples in the laboratory, identified as Walleyes following Auer (1982), and enumerated. Walleye TLs ( $\mathrm{mm}$ ) were measured by using the manual measurement tool in Image-Pro Plus version 5.1 (Media Cybernetics, Bethesda, Maryland). Samples containing considerable amounts of detritus were subsampled by using a Folsom plankton splitter. Significant differences in mean TL of Walleye larvae among emergence dates $(<210$ cumulative degree-days [CDDs] and $\geq 210$ CDDs; CDDs $=$ the sum of average daily temperatures starting from April 1) and between years were tested by using ANOVA. Significant differences in Walleye larval densities between nighttime $(n=4)$ and daytime $(n=7)$ sampling events at Maple Island Road were compared by using a Wilcoxon rank-sum test.

Walleye larval densities (number $/ 100 \mathrm{~m}^{3}$ ) were estimated as the number of larvae in a sample divided by the volume of water filtered (estimated from the flow meter in the mouth of each drift net). Average volume filtered per $10 \mathrm{~min}$ at a site over the study period was substituted in cases where detritus disabled the flow meter; this situation occurred $7 \%$ of the time in 2009 and $3 \%$ of the time in 2010. The number of Walleye larvae drifting over the 10-min sample period was estimated as the mean larval density multiplied by river discharge $\left(\mathrm{m}^{3} / \mathrm{s}\right)$. These nightly estimates were then extrapolated over the 24-h drift period to estimate the number of Walleye larvae emigrating each day, as there was no significant difference in the densities of larvae sampled during daytime and nighttime at the Maple Island Road site. Numbers of larvae emigrating on unsampled nights were estimated by using Bayesian techniques (see below), and the total number of Walleyes emigrating from each site was calculated as the sum of the 24-h estimates and interpolations.

Spatiotemporal variation, abundance, and survival of larvae.-We estimated the proportional contribution of spatial and temporal variance components in the larval Walleye drift to help identify the scale at which abiotic factors contribute to fluctuations in abundance. Sample densities were converted to the number of fish larvae per $100 \mathrm{~m}^{3}$ and were rounded to the nearest whole number to allow the use of a discrete Poisson distribution. A Bayesian hierarchical Poisson ANOVA was used to account for an unbalanced data structure and count data bounded at zero. Under these data conditions, which are often encountered with observational data, Bayesian hierarchical methods provide improved estimates of variance components relative to traditional maximum likelihood-based ANOVA methods (Qian and Shen 2007; Gelman et al. 2014). The ANOVA model included three factors and an error term: the site factor, representing small-scale spatial variation; day and year factors, representing small- and large-scale temporal variation, respectively; and the error term, representing unexplained variation that was attributable to small-scale, within-site variation in larval density. We used normal distributions with low-information priors for the mean (normal $[0,0.001]$ ) and SD (folded- $T[0,0.01,2]$ ) to represent model parameters. We used Markov chain-Monte Carlo (MCMC) methods in OpenBUGS (Lunn et al. 2009) to sample posterior distributions, including three mixing chains with 5,000 iterations each, a 1,000-iteration burn-in period, and thinning of samples to 1 out of every 10. OpenBUGS was called through program $\mathrm{R}$ via the R2OpenBUGS package (Sturtz et al. 2005). Model convergence was assessed by using visual monitoring of chain history and by calculating the $\hat{r}$ statistic (Gelman and Hill 2007). We report SDs of posterior model parameter estimates, which represent the proportional contribution of variation from each factor and unexplained variation.

Annual production of Walleye larvae at each site was estimated to help identify differences in abundance within our study; we also compared changes in abundance with results reported from previous studies of Walleyes in Great Lakes tributaries. We used a Bayesian state-space model, which was beneficial in that it (1) accounted for spatial and temporal variability, which is commonly encountered when sampling larval Walleyes in the drift (D'Amours et al. 2001; DuFour et al. 2014); (2) estimated unsampled days by using an autoregressive component, which shared information among days (Harvey and Fernandes 1989), making the reasonable assumption that the hatch of larval Walleyes was driven by a continuum of environmental factors and that days close to one another likely held similar values; and (3) propagated spatial, temporal, and model uncertainty into the final annual production estimates (Cressie et al. 2009; DuFour et al. 2014). Subsequently, annual production estimates were described as a probability distribution, fully acknowledging all sources of uncertainty. Low-information prior distributions were used throughout the model, which allowed the final estimates to be dominated by sampled density data. In general, the state-space model produced posterior daily density estimates in distributional form. These estimates were rescaled from density to abundance by multiplying by the average daily river discharge, which resulted in daily estimates of larval Walleye production that were also described with probability distributions. Daily production estimates were summed to generate annual estimates of larval Walleye production (see DuFour et al. 2014 for model specifics). We ran the model separately for each site 
(Pine Street, Thornapple, and Maple Island Road) and each year (2009 and 2010), resulting in six annual production estimates. We used MCMC methods in OpenBUGS (Lunn et al. 2009) to sample posterior distributions, including three mixing chains with 25,000 iterations each, a 5,000iteration burn-in period, and no thinning. Model convergence was assessed by using visual monitoring of chain history.

Survival of Walleye larvae $\left(S_{\text {larva }}\right)$ from upstream sites to downstream sites was calculated as the ratio of larval abundance at the downstream site (Maple Island Road) divided by larval abundance at the upstream site (Thornapple). Instantaneous daily mortality $(Z / d)$ of larvae was calculated as $Z / \mathrm{d}=\log _{e}\left(S_{\text {larva }}\right) / \mathrm{d}$. Walleye larvae that hatched from spawning grounds at or above the Thornapple site were assumed to travel from Thornapple to Maple Island Road in approximately $2 \mathrm{~d}$ based on hydraulic model results (M. Wiley, University of Michigan, personal communication). To determine the relative influences of temperature and discharge on larval survival, we calculated survival rates for Walleye larvae that hatched early in the season in cooler temperatures $(<210$ CDDs since April 1$)$ and for larvae that hatched later in warmer temperatures $(\geq 210$ CDDs since April 1).

\section{RESULTS}

\section{River Environment}

The Muskegon River environment was significantly warmer, had lower discharge, and exhibited less variability in 2010 than in 2009 (paired $t$-ratio $=-25.69, \mathrm{df}=89, P<$ 0.0001; Figure 2; Table S.2). Daily temperatures in April were $2^{\circ} \mathrm{C}$ warmer in 2010 than in 2009 . Average water temperature from March 31 to May 15-the time period when Walleye eggs and larvae were present in the Muskegon River

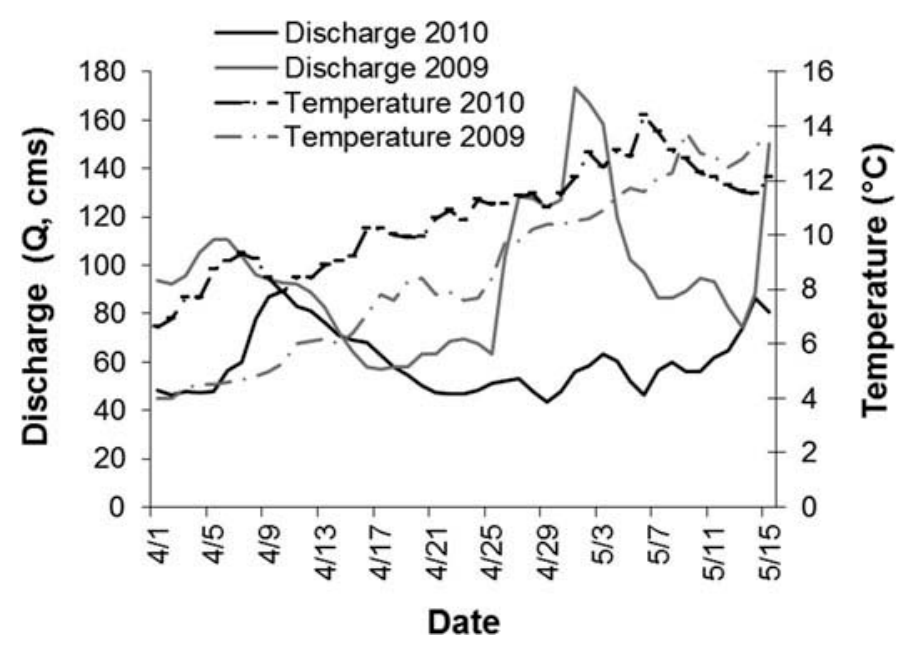

FIGURE 2. River discharge $\left(Q ; \mathrm{m}^{3} / \mathrm{s}\right)$ and water temperature measured near Croton Dam on the Muskegon River, Michigan (see Figure 1; U.S. Geological Survey gauging station 04121970), from April 1 to May 15, 2009-2010. —was $8.5^{\circ} \mathrm{C}$ (range $=3.9-13.8^{\circ} \mathrm{C}$; $\mathrm{CV}=37 \%$ ) in 2009 and $10.5^{\circ} \mathrm{C}$ (range $=5.6-14.4^{\circ} \mathrm{C} ; \mathrm{CV}=19 \%$ ) in 2010 . Average daily river discharge (USGS 2011) calculated for the same time period was $96 \mathrm{~m}^{3} / \mathrm{s}\left(\right.$ range $\left.=57-174 \mathrm{~m}^{3} / \mathrm{s} ; \mathrm{CV}=30 \%\right)$ in 2009 and $61 \mathrm{~m}^{3} / \mathrm{s}\left(\right.$ range $\left.=36.8-89.5 \mathrm{~m}^{3} / \mathrm{s} ; \mathrm{CV}=22 \%\right)$ in 2010. Peak discharge in $2010\left(\sim 90 \mathrm{~m}^{3} / \mathrm{s}\right)$ was half the peak discharge observed in $2009\left(\sim 175 \mathrm{~m}^{3} / \mathrm{s}\right)$. Peak discharge in 2010 occurred during the second week in April, whereas peak discharge in 2009 extended from late April to early May, with a secondary peak during the first week of April. Conductivity and $\mathrm{pH}$ values were lower in 2009 than in 2010, while velocity, depth, dissolved oxygen, and turbidity values were higher in 2009 than in 2010 (Table S.2).

Water quality variables differed less among larval drift sample sites than between years. Only temperature and turbidity values varied consistently among sites in each year, as values were higher at the Maple Island Road site than at upstream sites. In 2010 only, dissolved oxygen concentrations also were significantly higher at Maple Island Road than at upstream sites (Table S.2). Mean $( \pm \mathrm{SE})$ water quality values averaged over both years and sites were as follows: temperature was $11.6 \pm 0.2^{\circ} \mathrm{C}$; dissolved oxygen was $10.1 \pm 0.09 \mathrm{mg}$ / $\mathrm{L}$; $\mathrm{pH}$ was $8.0 \pm 0.01$; specific conductivity was $318 \pm 4 \mu \mathrm{S} /$ $\mathrm{cm}$; and turbidity was $2.68 \pm 0.51$ NTU.

The river substrate at egg mat placement sites was predominantly hard, consisting mainly of pebble and gravel (Table S.3). There was no significant difference in relative composition of all hard substrate types combined among sites $\left(\chi^{2}=0.039, \mathrm{df}=2, P=0.98\right)$ or between years $\left(\chi^{2}=\right.$ $0.231, \mathrm{df}=1, P=0.13)$.

\section{Walleye Spawner Size, Egg Density, and Survival}

Over the first 2 weeks of the spawning season, 100 Walleye females were sampled in 2009, and 106 females were sampled in 2010. Spawner length ranged from 526 to $800 \mathrm{~mm}$ TL $($ mean $=659 \pm 8 \mathrm{~mm})$, and spawner weight ranged from 1.4 to $6.0 \mathrm{~kg}$ (mean $=3.3 \pm 0.1 \mathrm{~kg}$ ). Mean TL of Walleye females was smaller in 2009 than in 2010, but female weight did not differ between years (Table S.4). Walleye females that were sampled during the first week of the spawning season were significantly larger in TL and weight than females that were sampled during the second week (Table S.4).

In both 2009 and 2010, Walleyes deposited eggs at sample sites from the last week of March to the second week of April (Supplementary Figure S.1 available in the online version of this paper). Three-week peak mean egg densities occurred during the weeks of April 7, 14, and 21 in 2009 and during the weeks of April 5, 12, and 19 in 2010. In 2009, data for the last 2 weeks of sampling were not available from Thornapple site 2 because mats were removed by high flows. Peak mean egg density was found to be significantly affected by year $\left(F_{1,24}=76.76, P<0.01\right)$, site $\left(F_{5,24}=\right.$ $35.72, P<0.01)$, and the site $\times$ year interaction $\left(F_{5,24}=\right.$ 


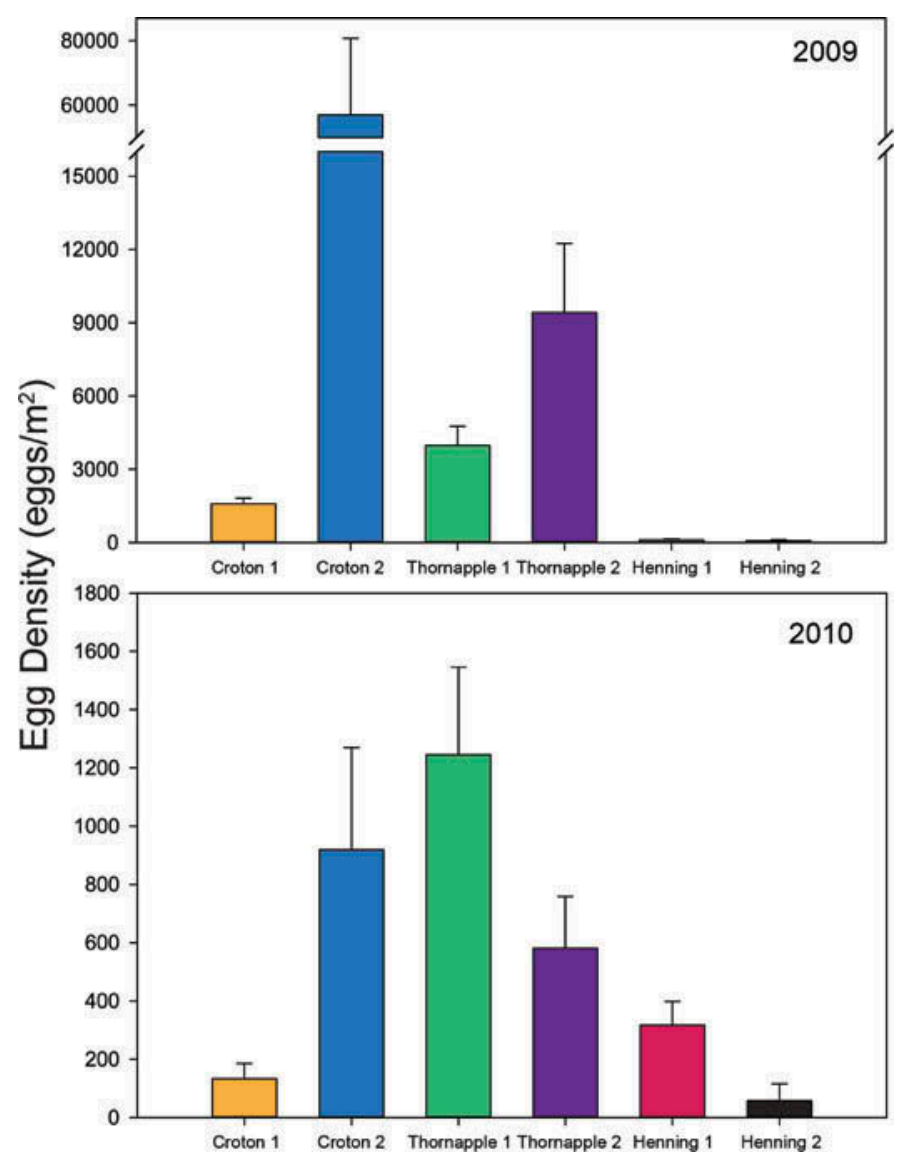

FIGURE 3. Three-week peak mean (+SE) Walleye egg density on mats deployed at various sites (see Figure 1) in the Muskegon River during 2009 and 2010. Note that the egg densities are untransformed values and that the $y$-axis scale differs between the two panels.

25.83, $P<0.01$; Figure 3). Thus, we found evidence that peak mean egg densities were higher in 2009 and differed among sites (see the online Supplement for a description of specific differences). In 2009 and 2010, peak mean egg densities on mats were negatively correlated $(\rho=-0.71)$ with site proximity to Croton Dam, suggesting that egg deposition decreased as distance from the dam increased. Peak mean egg density was not significantly correlated with any other environmental variable (mean water temperature, depth, velocity, $\mathrm{pH}$, turbidity, dissolved oxygen concentration, or substrate composition).

\section{Egg Survival on Mats}

Walleye egg survival on mats was considerably lower in 2009 than in 2010 (Table 1). No stage-1 or stage-3 Walleye eggs were deposited at Croton Dam site 1 or Henning Park site 2 in 2010, so egg survival at those sites could not be estimated. In 2009, egg survival averaged over all six sites was $18 \%$; in 2010 , egg survival was $35 \%$ (averaged over the four sites where eggs had been deposited). Croton Dam site
TABLE 1. Annual egg survival $(S)$, instantaneous egg mortality rate $(Z)$, and the number of days an average egg took to reach stage-3 status $(t)$ for Walleye eggs collected on mats deployed at three sites in the Muskegon River, Michigan, during 2009 and 2010 (CR = Croton Dam; TA = Thornapple; HP = Henning Park; Figure 1).

\begin{tabular}{lcccllll}
\hline & \multicolumn{3}{c}{2009} & & \multicolumn{3}{c}{2010} \\
\cline { 2 - 4 } \cline { 6 - 8 } Site & $t$ & $S$ & $Z$ & & \multicolumn{1}{c}{$t$} & \multicolumn{1}{c}{$S$} & \multicolumn{1}{c}{$Z$} \\
\hline CR 1 & 21.8 & 0.23 & 0.07 & No eggs $^{\mathrm{b}}$ & No eggs & No eggs \\
CR 2 & 20.2 & 0.13 & 0.10 & 15.7 & 0.82 & 0.01 \\
TA 1 & 20.6 & 0.22 & 0.07 & 16.0 & 0.48 & 0.05 \\
TA 2 & N/A & 0.00 & N/A & 19.4 & 0.10 & 0.12 \\
HP 1 & 24.3 & 0.50 & 0.03 & & N/A & 0.00 & N/A \\
HP 2 & N/A & 0.00 & N/A & No eggs & No eggs & No eggs \\
\hline
\end{tabular}

a "N/A" indicates that no stage-3 eggs were collected at the site; therefore, we assumed that survival was zero because stage-1 eggs were collected.

b "No eggs" indicates that no stage- 1 or stage- 3 eggs were collected at the site.

2 experienced the greatest increase in annual egg survival between years: from $13 \%$ in 2009 to $82 \%$ in 2010 . However, a decrease in egg survival was observed at Henning Park site 1, from $50 \%$ in 2009 to $0 \%$ in 2010 (Table 1). Mean egg survival in 2010 and egg survival averaged across both years decreased with distance downstream, whereas in 2009 mean egg survival was highest at Henning Park site 1. There was no significant relationship between the estimated egg survival rates and any of the environmental variables measured.

\section{Egg Survival in Incubators}

In 2009 and 2010, Walleye egg survival in incubators within the Muskegon River was relatively high and was similar to survival in the control incubators at Thompson State Fish Hatchery. Mean egg survival in control incubators was $76.0 \pm 5.3 \%(n=3)$ in 2009 and $43.3 \pm 18.0 \%(n=3)$ in 2010 . In 2009, one gang of incubators (28-d incubation period at Henning Park site 1) was lost due to vandalism. Nevertheless, similar results were obtained in both years. In 2009, Walleye egg survival was not significantly affected by site $\left(F_{5,21}=\right.$ 1.53, $P=0.22)$, the length of the incubation period $\left(F_{1,21}=\right.$ $2.90, P=0.10)$, or the site $\times$ incubation period interaction $\left(F_{4}\right.$, ${ }_{21}=2.71, P=0.05$ ). Walleye egg survival at $21 \mathrm{~d}$ ranged from $30.7 \%$ to $71.3 \%$ (average over all sites $=50.3 \%$; Table 2 ), and survival at $28 \mathrm{~d}$ ranged from $21.3 \%$ to $54.7 \%$ (average over all sites $=40.7 \%$ ). In 2010, Walleye egg survival was significantly affected by site $\left(F_{5,23}=3.27, P=0.02\right)$; however, the length of the incubation period $\left(F_{1,23}=3.94, P=0.05\right)$ and the site $\times$ incubation period interaction were not significant $\left(F_{5,23}=0.70, P=0.62\right)$. Egg survival was significantly higher at Croton Dam site 2 than at Henning Park site 2 (i.e., the sites with the highest and lowest survival rates, respectively) but was not significantly different among the other sites (Tukey's 
TABLE 2. Mean annual percent survival (with coefficient of variation $[\mathrm{CV}$, $\%$ ] in parentheses) of Walleye eggs in incubator chambers deployed at three Muskegon River sites during 2009 and 2010 (values are means for three replicate egg chambers per site; $\mathrm{CR}=$ Croton Dam; TA = Thornapple; HP = Henning Park; see Figure 1).

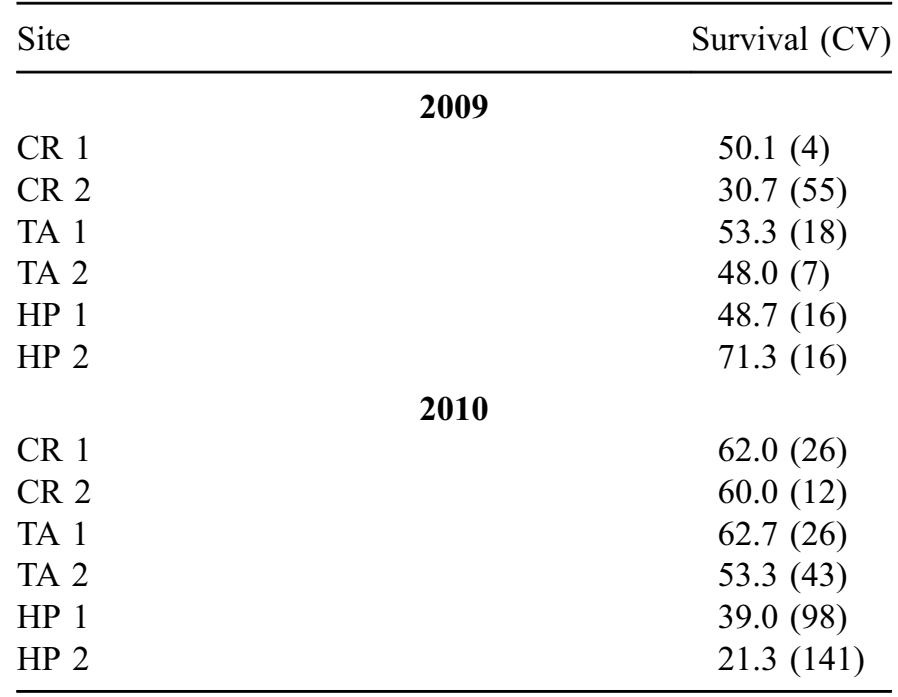

HSD test: $P \geq 0.50)$. Walleye egg survival at $7 \mathrm{~d}$ ranged from $37.3 \%$ to $94.0 \%$ (average over all sites $=66.5 \%$ ), and egg survival at $21 \mathrm{~d}$ ranged from $21.3 \%$ to $62.6 \%$ (average over all sites $=49.7 \%$ ).

Although there was not a significant year effect $\left(F_{1,23}=\right.$ $0.01, P=0.91)$ or site effect $\left(F_{5,23}=0.70, P=0.63\right)$ on mean Walleye egg survival at $21 \mathrm{~d}$, the site $\times$ year interaction was significant $\left(F_{5,23}=3.88, P=0.01\right)$. Egg survival at Henning Park site 2 was greater in 2009 (71.3\%) than in $2010(21.3 \%)$. When all sites were considered, results of linear regression analysis indicated that there was no significant relationship between egg survival in incubators and any environmental variable. However, when the Henning Park 2010 survival data were removed, egg survival over all other sites was negatively related to flow velocity $\left(F_{1,9}=11.61, P=0.009\right.$, $\left.R^{2}=0.59\right)$ and was positively related to temperature $\left(F_{1,9}=\right.$ 5.16, $P=0.05, R^{2}=0.39$ ).

\section{Walleye Larval Catch, Length, Density, and Survival Rate}

In total, 242 larval drift samples were collected for analysis; the volume of water filtered across all samples was lower in $2010\left(\right.$ mean $\left.\pm \mathrm{SE}=62 \pm 1.4 \mathrm{~m}^{3}\right)$ than in $2009\left(81 \pm 1.6 \mathrm{~m}^{3}\right)$. Despite the lower flows in 2010, many more Walleye larvae were caught during that year (2,247 larvae) than over the slightly longer sample period in 2009 (581 larvae). Mean TL of Walleye larvae varied between years $\left(F_{1,1,941}=112.58, P<\right.$ $0.0001)$ and between dates $\left(F_{1,1,941}=2,862.05, P<0.0001\right)$. Walleye larvae were smaller on average in 2009 (least-squares mean $\pm \mathrm{SE}=7.2 \pm 0.06 \mathrm{~mm} ; n=453)$ than in $2010(7.5 \pm$ $0.02 \mathrm{~mm} ; n=1,491)$. Within each year, larvae were smaller
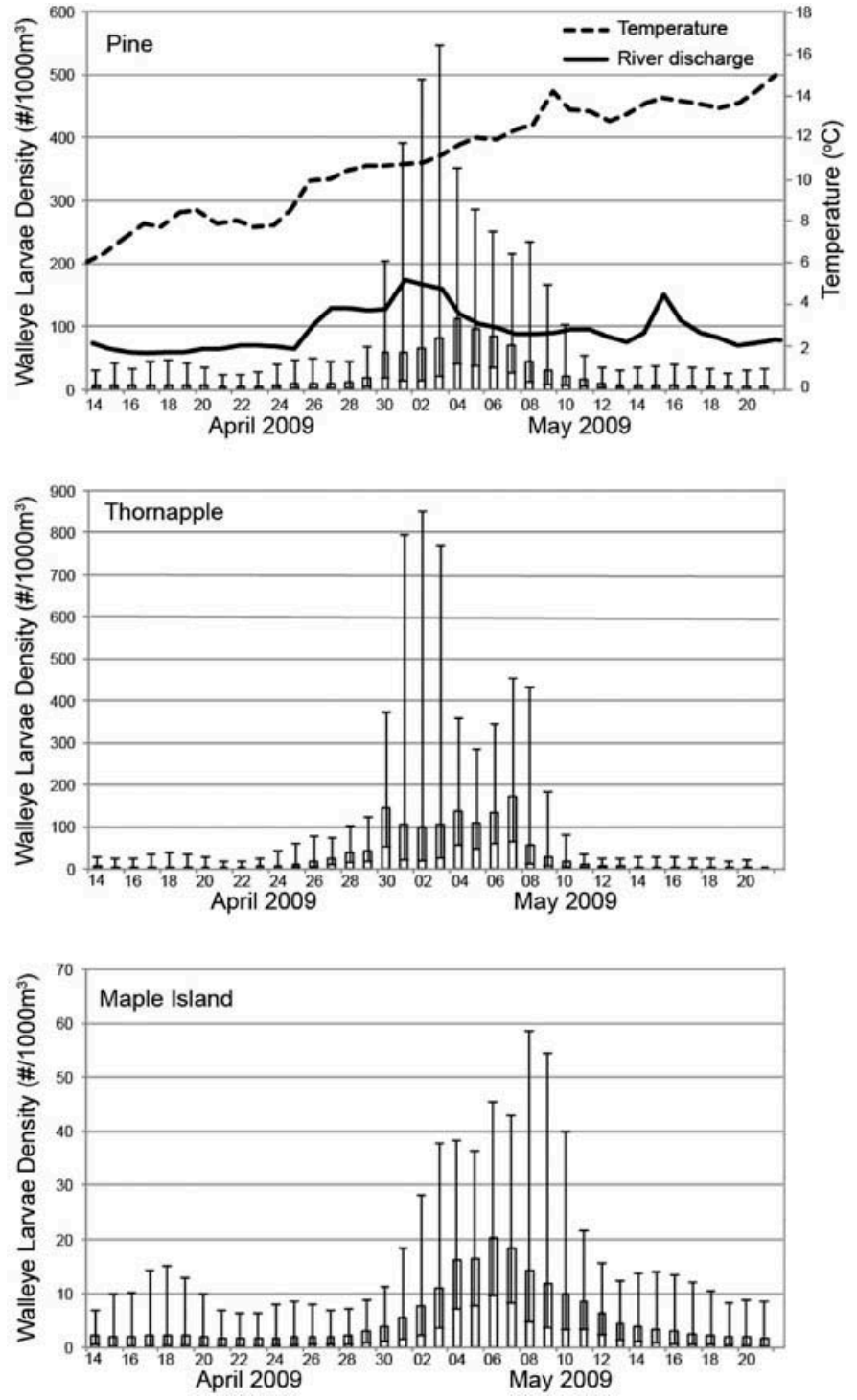

FIGURE 4. Bayesian estimates of the median density of Walleye larvae at three sites in the Muskegon River during April 14-May 21, 2009, and corresponding water temperature and river discharge $\left(\mathrm{m}^{3} / \mathrm{s}\right)$ measured at Croton Dam. Sites (see Figure 1) from upstream to downstream are Pine Street near Croton Dam (upper panel); Thornapple (middle panel); and Maple Island Road (lower panel). Error bars represent $2.5 \%$ and $97.5 \%$ credible intervals around the median values. The $y$-axis scale differs among the panels.

when hatched earlier in colder temperatures $(<210$ CDDs from April 1 ; mean $\mathrm{TL} \pm \mathrm{SE}=6.6 \pm 0.04 \mathrm{~mm} ; n=611)$ than when hatched later in warmer temperatures ( $\geq 210$ CDDs; $8.0 \pm$ $0.03 \mathrm{~mm} ; n=1,333)$.

Densities of Walleye larvae varied significantly between years $\left(F_{1,245}=13.663, P<0.001\right)$ and among sites $\left(F_{2,245}\right.$ $=4.707, P<0.01)$, while total variation in larval density was dominated by small-scale day-to-day fluctuations. Walleye larval densities were higher and peaked earlier in 2010 than in 2009. Larval densities peaked between April 30 and May 11 in 2009 (Figure 4), whereas they peaked 

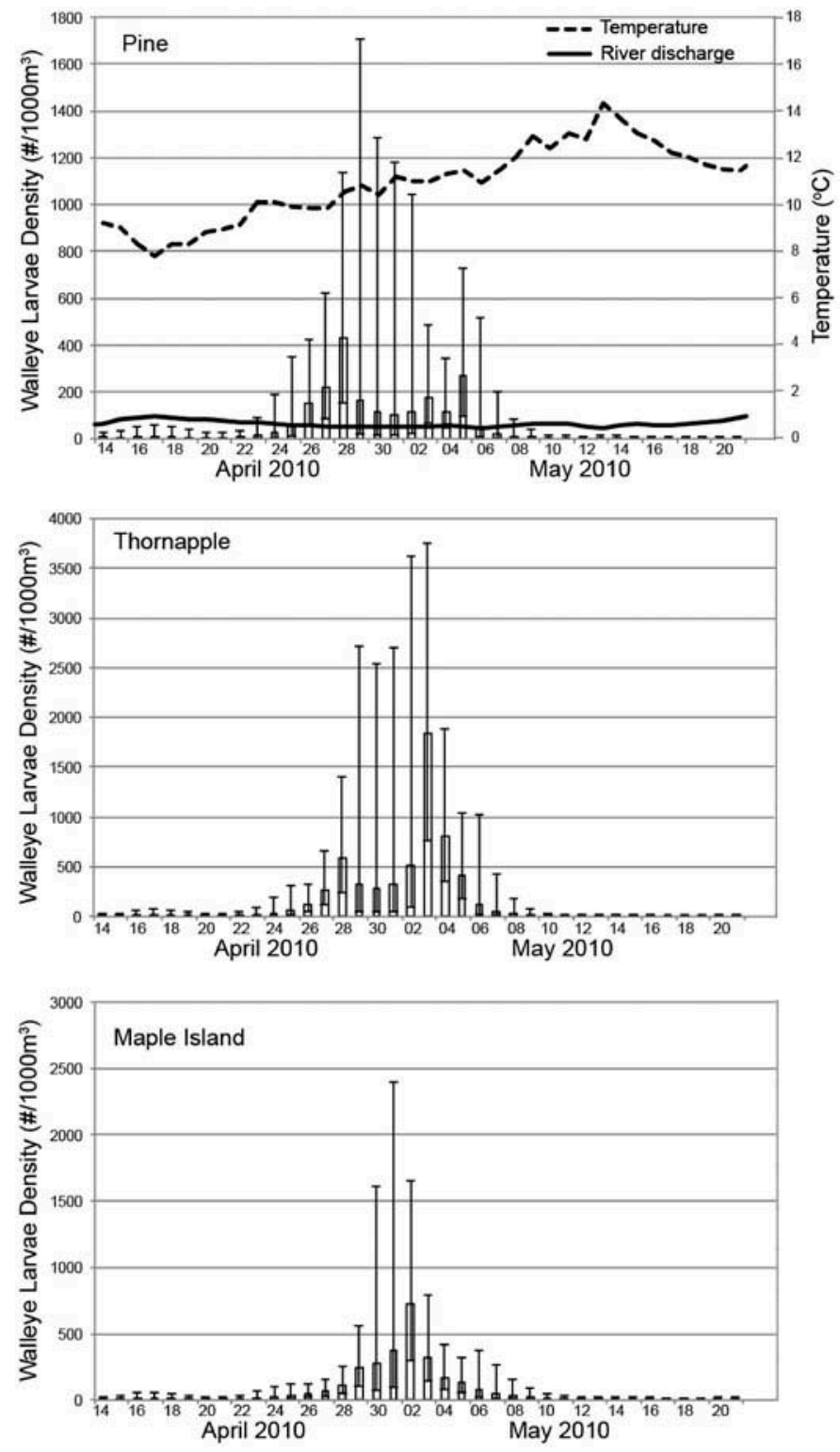

FIGURE 5. Bayesian estimates of the median density of Walleye larvae at three sites in the Muskegon River during April 7-May 20, 2010, and corresponding water temperature and river discharge $\left(\mathrm{m}^{3} / \mathrm{s}\right)$ measured at Croton Dam. Sites (see Figure 1) from upstream to downstream are Pine Street near Croton Dam (upper panel); Thornapple (middle panel); and Maple Island Road (lower panel). Error bars represent $2.5 \%$ and $97.5 \%$ credible intervals around the median values. The $y$-axis scale differs among the panels.

between April 17 and May 2 in 2010 (Figure 5). Average larval densities in both 2009 and 2010 were significantly higher at the upstream sites (Pine Street and Thornapple) than at the downstream site (Maple Island Road; Table 3). Temporal variability in larval density was greater than spatial variability in the Muskegon River: day-to-day variability predominated, followed by year-to-year variability (reported as $\log _{e}[\mathrm{SD}]$; Table 4). Within-site spatial variability in larval density was low in comparison with other sources, whereas
TABLE 3. Estimates of Walleye larval density (number $/ 1,000 \mathrm{~m}^{3}$; leastsquares mean $[\mathrm{LSM}] \pm \mathrm{SE}$ ) at each drift sampling site (Figure 1) in the Muskegon River during April-May 2009 and 2010. Differences in larval densities among sites and between years are indicated by the $F$-test results.

\begin{tabular}{|c|c|c|c|c|}
\hline Site or factor & $\mathrm{LSM} \pm \mathrm{SE}$ & df & $F$-ratio & $P>F$ \\
\hline \multicolumn{5}{|c|}{2009 Larval density } \\
\hline Pine Street & $3.3 \pm 4.3$ & & & \\
\hline Thornapple & $5.2 \pm 4.3$ & & & \\
\hline Maple Island Road & $0.6 \pm 4.3$ & & & \\
\hline Average & $3.0 \pm 2.5$ & & & \\
\hline \multicolumn{5}{|c|}{2010 Larval density } \\
\hline Pine Street & $10.0 \pm 4.0$ & & & \\
\hline Thornapple & $27.6 \pm 4.0$ & & & \\
\hline Maple Island Road & $8.6 \pm 4.0$ & & & \\
\hline Average & $15.4 \pm 2.3$ & & & \\
\hline \multicolumn{5}{|c|}{$F$-Test results } \\
\hline Year & & 1 & 13.663 & 0.0003 \\
\hline Site & & 2 & 4.767 & 0.0099 \\
\hline Site $\times$ year & & 2 & 2.251 & 0.108 \\
\hline Corrected total & & 245 & 5.717 & 0.001 \\
\hline
\end{tabular}

among-site variability had the lowest contribution to total variability. Diel sampling of Walleye larval drift at the Maple Island Road site revealed no significant difference $\left(\chi^{2}=0.797, \mathrm{df}=1, P=0.232\right)$ in catches of Walleye larvae between daytime and nighttime.

Assuming that larval Walleye drift at night was representative of drift that occurred during other periods, we estimated total annual production at each site in each year (Figure 6). Median larval abundance at the Pine Street site was similar in 2009 and 2010, as indicated by substantial overlap in the $95 \%$ credible intervals (CIs). However, differences in larval abundance between the two study years began to increase as fish moved downstream: median abundance at Thornapple was lower in 2009 than in 2010, and the overlap between the 95\% CIs also decreased. The total number of larvae produced at the downstream-most site (Maple Island Road) near the nursery area in 2009 was 2.1 million $(95 \% \mathrm{CI}=1.3-3.8$

TABLE 4. Summary of variance (expressed as $\log _{e}[\mathrm{SD}]$ ) in median Walleye larval density (with $50 \%$ and $95 \%$ credible limits [CLs]) at different temporal and spatial scales (replicate nets at a site [extra], among sites, among days, and between years) as determined using Bayesian hierarchical models.

\begin{tabular}{lccccc}
\hline & Lower & Lower & & Upper & Upper \\
Source & $95 \% \mathrm{CL}$ & $50 \% \mathrm{CL}$ & Median & $50 \% \mathrm{CL}$ & $95 \% \mathrm{CL}$ \\
\hline Year & 1.034 & 1.261 & 1.383 & 1.507 & 1.726 \\
Day & 1.856 & 1.954 & 2.006 & 2.059 & 2.163 \\
Site & 0.643 & 0.761 & 0.826 & 0.891 & 1.009 \\
Extra & 0.918 & 0.956 & 0.977 & 0.997 & 1.038 \\
\hline
\end{tabular}




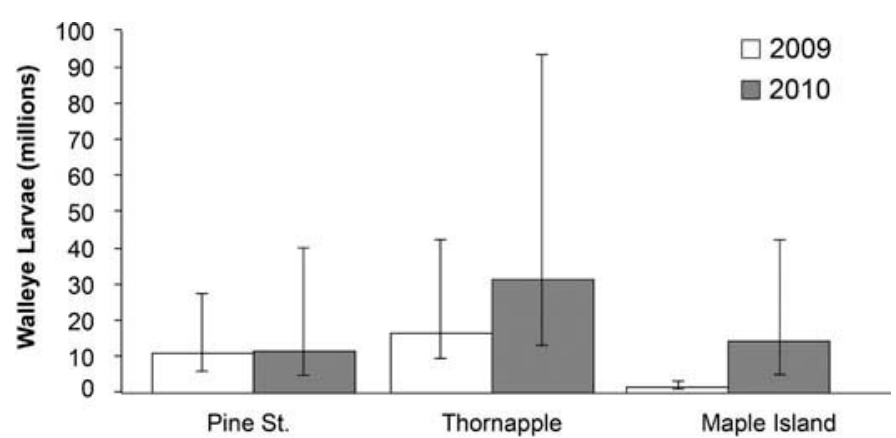

FIGURE 6. Bayesian estimates of annual median Walleye larval abundance at three stations in the lower Muskegon River (see Figure 1). Estimates are based upon daily discharge at Croton Dam and posterior daily densities estimated for individual sites. We assumed a constant 24-h drift. Error bars represent 2.5\% and $97.5 \%$ credible intervals around the median values.

million larvae), which was sevenfold lower than the 2010 estimate of 14.8 million larvae $(95 \% \mathrm{CI}=9.4-27.7$ million larvae; Figure 6). The annual production patterns indicated that larvae experienced greater mortality during the downstream drift in 2009.

The median survival of Walleye larvae from Thornapple to Maple Island Road was lower in $2009\left(S_{\text {larva }}=12.7 \%\right.$; $95 \% \mathrm{CI}=9.0-13.3 \%)$ than in $2010\left(S_{\text {larva }}=47.3 \%\right.$; $95 \% \mathrm{CI}$ $=44.6-52.7 \%)$. In 2009, the survival of Walleye larvae that hatched early in the season (before May 1) and in colder temperatures $(<210$ CDDs from April 1) was similar to the survival of larvae that hatched in warmer temperatures (246 CDDs) after May $2\left(S_{\text {larva }}=13 \%\right.$ for early hatching larvae and $14 \%$ for later-hatching larvae). However, in 2010, the survival of larvae that hatched early (before April 23) and in cooler temperatures was much higher than the survival of larvae that hatched in warmer temperatures (296 CDDs) after April $24\left(S_{\text {larva }}=82 \%\right.$ for early hatching larvae and $16 \%$ for later-hatching larvae). In each year, river discharge was lower (by $\sim 400 \mathrm{~m}^{3} / \mathrm{s}$ ) for early hatching larvae than for late-hatching larvae.

\section{DISCUSSION}

Our results suggest that abiotic variables, specifically water temperature and river discharge, are primary factors affecting the survival of Walleye eggs and larvae in the Muskegon River. Factors that are known to influence the survival of Walleyes prior to the juvenile stage include (1) water temperature and river discharge during the egg incubation and larval emigration periods (Mion et al. 1998; Jones et al. 2003); (2) the size and quality of Walleye eggs and larvae (Venturelli et al. 2010); (3) prey availability (Quist et al. 2004); and (4) predation on the relatively immobile eggs and larvae (Mion et al. 1998; Roseman et al. 2006; Fielder et al. 2007). These factors often are regionally important and representative of biotic and abiotic alterations to Walleye spawning habitat. Previous studies of the Muskegon River have linked low recruitment of naturally spawned Walleyes to poor egg survival (Day 1991; Ivan et al. 2010).

Walleye egg deposition occurred over a short period of time ( $\sim 3$ weeks in both 2009 and 2010) and at a highly localized scale, with the majority of egg deposition occurring on mats over hard substrates from Croton Dam to Thornapple, a distance of 13.5 river kilometers. This was evident from the negative correlation between peak mean egg density and distance from the dam. Walleye egg densities in our study were similar to those reported in earlier work on the Muskegon River. Ivan et al. (2010) estimated river average egg densities of $28,444 \mathrm{eggs} / \mathrm{m}^{2}$ in 2005 and $6,539 \mathrm{eggs} / \mathrm{m}^{2}$ in 2006; our estimate of peak mean egg density on mats $\left(12,029 \mathrm{eggs} / \mathrm{m}^{2}\right)$ was intermediate between those values. In 2010, estimated peak mean egg density was considerably lower at $285 \mathrm{eggs} / \mathrm{m}^{2}$, but this may have been partly an artifact of our sampling regime. The same sites were sampled during both years to allow for comparisons, but water depths were much lower in 2010, thus forcing the Walleyes to spawn in deeper areas adjacent to our sites. Although egg densities on mats were an order of magnitude lower in 2010 than in 2009, our 2009 estimates were in agreement with previous estimates for the Muskegon River.

Egg survival in incubators and mats was sufficient to produce a relatively high abundance of Walleye larvae in the Muskegon River. Average survival of Walleye eggs in incubators was nearly $50 \%$ across all sites in both years; Ivan et al. (2010) reported that egg survival rates in incubators were $24 \%$ in 2003 and $50 \%$ in 2004 . We suspect that egg survival in incubators approaches the theoretical limit for survival in the river, as eggs within incubators are not vulnerable to predation and may be less impacted by the physical habitat; for instance, they are less likely to be entombed in the substrate (which would reduce survival) or displaced from the substrate (which could result in settlement in low-quality habitats and mortality due to physical abrasions). Eggs on mats are more likely to experience mortality from predation (i.e., predators have greater access to eggs on mats than eggs in incubators), and changes in river discharge could cause eggs to be displaced from the mats. Egg displacement from mats due to changes in discharge or movement during surveys could result in underestimates of density and survival. As expected, average survival across sites was lower for eggs on mats than for eggs in incubators, a result that was also observed by Ivan et al. (2010), although survival still equaled or exceeded $18 \%$. Interestingly, average Walleye egg survival on mats across sites was about twice as high in 2010 (35\%) than in 2009 (18\%), but egg deposition on mats was about 42 times higher in 2009 than in 2010. However, discharge was also higher in 2009 than in 2010, as discussed above.

Egg transport and fine sediment accumulation have been linked to decreased Walleye egg survival (Roseman et al. 1996). Johnson (1961) found that the survival of Walleye 
eggs was related to substrate composition; on average, only $2.9 \%$ of eggs survived to the eyed stage when incubated in areas containing high amounts of sand and silt, whereas $17.7 \%$ survived when incubated on gravel-cobble substrates. Survival of Walleye eggs on mats in the Muskegon River during 2005 and 2006 ( $S=2 \%$; Ivan et al. 2010) was much lower than the rates we observed in 2009 and 2010. The differences in survival between the two studies may have been related to colder temperatures in 2005; however, we believe that these differences are more likely attributable to differences in estimation procedure than to differences in physical conditions. Ivan et al. (2010) estimated egg survival rates based on initial egg abundance by using estimates of population size, fecundity, and egg fertilization rate, and they applied daily egg mortality rates from egg density data. When we re-analyzed Ivan et al.'s (2010) egg density data for 2005, estimated egg survival on mats ranged from $3 \%$ to $45 \%$ and averaged $20 \%$, close to our mean annual values of $18 \%$ and $30 \%$. Average daily discharge rates during the Walleye egg incubation period (March 23-May 5) in the Muskegon River were higher in $2009\left(96 \mathrm{~m}^{3} / \mathrm{s}\right)$ than in $2010\left(61 \mathrm{~m}^{3} / \mathrm{s}\right)$. Furthermore, the seasonal peak discharge rate during Walleye spawning in $2009\left(174 \mathrm{~m}^{3} / \mathrm{s}\right)$ was higher than that in $2010\left(133 \mathrm{~m}^{3} / \mathrm{s}\right)$. The combination of high sustained discharge and high peak discharge in 2009 may have contributed to the greater egg mortality and lower abundance of newly hatched Walleye larvae in 2009 compared with 2010; egg survival in our incubators was negatively related to flow velocity at most sites.

Annual differences in Walleye egg density and larval production in the Muskegon River suggest that variability in early life survival may be related to relatively short temporal changes in the physical environment during spawning and incubation. Walleye egg densities were higher but larval production was lower in 2009 than in 2010; river temperature and discharge over the same period (April 1-30) were also lower and more variable in 2009 than in 2010. Physical habitat suitability modeling of the Muskegon River (Ivan et al. 2010) confirmed that slower water velocities and warmer temperatures like those experienced in 2010 should have provided more suitable habitat for Walleye eggs. Although we found no statistical relationship between flow velocity and egg survival on mats, we did find a negative trend between flow velocity and egg survival in incubators. Mion et al. (1998) reported that higher survival (but not higher production) of Walleye larvae occurred under slower river flows in Lake Erie tributaries.

Water temperature also plays an important role in Walleye egg development and survival. The average temperature during the Walleye egg incubation period in the Muskegon River was $6.9 \pm 0.4^{\circ} \mathrm{C}$ (mean $\pm \mathrm{SE}$ ) during April 1-30, 2009, and 7.8 $\pm 0.4^{\circ} \mathrm{C}$ during March 25-April 22, 2010; these values were several degrees colder than the optimum temperature range for Walleye development during egg incubation $\left(9-15^{\circ} \mathrm{C}\right.$; Colby et al. 1979). Walleye eggs are known to be extremely sensitive to environmental disturbance during the first $10 \mathrm{~d}$ postfertilization (Latif et al. 1999). Ivan et al. (2010) found that annual differences in egg survival were correlated with differences in average water temperature during the first $10 \mathrm{~d}$ postfertilization. We also detected positive relationships between water temperature and egg survival in incubators at most sites. In our study, water temperatures averaged $4.6 \pm 0.3^{\circ} \mathrm{C}$ during the first $10 \mathrm{~d}$ postfertilization in 2009 -well below the average 10-d temperature $\left(6^{\circ} \mathrm{C}\right)$ that is considered favorable for egg survival after fertilization (Latif et al. 1999). In 2010, the average water temperature during the first $10 \mathrm{~d}$ postfertilization was $5.5 \pm$ $0.4^{\circ} \mathrm{C}$, which is closer to the favorable $6^{\circ} \mathrm{C}$ temperature but is still below optimum.

Differences in Walleye larval density among sites are likely related to differences in proximity to spawning locations. In contrast to Day's (1991) study of Walleye larvae in the Muskegon River during 1986, we observed significantly lower densities of Walleye larvae at the downriver site (Maple Island Road) than at sites further upstream in both years. Walleyes are known to spawn on gravel-cobble substrates (Raabe and Bozek 2015), which are found primarily upstream of the Thornapple site, rather than on sandy substrates, which are common in the lower river. We cannot explain why Day (1991) found higher catches of Walleye larvae at the Maple Island Road site than at upstream sites. Perhaps Walleyes used flooded wetlands in the lower river for spawning during that study, which may have contributed additional larval production, as was observed by Priegel (1970) in the Lake Winnebago system, Wisconsin.

Hatching times and densities of Walleye larvae were comparable to those identified during an earlier study of the Muskegon River. Day (1991) found that mean larval Walleye densities at six sites on the Muskegon River in 1986 peaked on May 3 at 9-34 larvae $/ 100 \mathrm{~m}^{3}$; this density was lower than the peak of 229 larvae $/ 100 \mathrm{~m}^{3}$, which we observed at the Thornapple site during late April 2010. We estimated the number of Walleye larvae emigrating from the Muskegon River during Day's (1991) study at approximately 913,000 larvae, similar to our estimated number of emigrating larvae in 2009 and one-tenth the estimate for 2010. Although variation in sampling methods between the two studies may partly account for the difference in estimated larval emigration from the spawning grounds, we suspect that the difference was primarily due to differences in the physical environment. For example, Day (1991) sampled larvae during the daytime, whereas we conducted larval sampling at night; Day (1991) sampled from nets attached to a boat in mid-river, while we sampled from nets suspended between anchors and floats. However, both studies sampled the same sites before, during, and after the peak in Walleye larval drift.

Spatial and temporal variation in the larval drift may provide insight into the factors controlling larval fish production in rivers. Variation in the larval drift can be influenced by many factors, including the timing of spawning events (Pritt 
et al. 2013); the environmental conditions that dictate hatching (Koenst and Smith 1976), transport (Wolter and Sukhodolov 2008), and survival (Mion et al. 1998); and the behavior of individuals in the drift (Pavlov et al. 2008; Lechner et al. 2014). Within the Muskegon River, temporal variability (among days and between years) was greater than spatial variability (within sites and among sites), and day-to-day fluctuations were the largest source. This pattern was similar to that observed in the Maumee River, Ohio, a much larger system where small-scale temporal and spatial variability was predominant (DuFour et al. 2014). Such patterns indicate that factors controlling the riverine production of larval Walleyes operate over short temporal scales (e.g., fluctuations in water temperature and discharge) and that consistency in larval production may depend on the overall stability of environmental conditions within each system.

Our estimates of Walleye larval abundance were generally lower than those reported for other Great Lakes tributaries, but our survival estimates were comparable with those from other Great Lakes studies (Table S.5). Larval Walleye abundances in the Muskegon River during 2009-2010 were approximately 10-fold lower than those in the Maumee River during 19931995 (Mion et al. 1998) or during 2010-2011 (DuFour et al. 2014) and were similar to those reported for the Sandusky River, Ohio, during 1993-1995 (Mion et al. 1998) and for the Saginaw River, Michigan, during the 1980s (Jude 1992; Table S.5). Prior estimates of adult spawner abundance ( 40,000 spawners) in the Muskegon River (Hanchin et al. 2007) also were lower than those estimated for the Maumee River (Pritt et al. 2013; Table S.5). A recent estimate of larval survival in the Maumee River was $37 \%$, intermediate to our annual survival estimates. Differences in Walleye larval abundance and survival rate among watersheds may be related to differences in the landscape and local physical habitat conditions that affect spawning habitat suitability and egg survival (Jones et al. 2003; Anderson et al. 2006); the annual variability in environmental conditions; the incidence of predation (Corbett and Fowles 1986; Fielder et al. 2007); and the abundance and fecundity of adult spawners (Schneider et al. 1991; Madenjian et al. 1996).

Factors influencing temporal variation in Walleye larval survival and production in the Muskegon River were similar to those reported for other Great Lakes tributaries. Mion et al. (1998) reported that in the Maumee and Sandusky rivers, high Walleye larval survival rates (but not abundances) were correlated with slower flows and typically occurred during the middle third of the larval emergence season. Those authors suggested that low survival of Walleye larvae later in the larval emergence period may have resulted from predation associated with spawning migrations of omnivores such as the White Perch Morone americana and White Bass Morone chrysops. In 2010, we also observed higher survival of Walleye larvae that hatched earlier in the season, which resulted in high larval production at the downstream site.
Although larval abundance upstream was 2.6-fold lower before April 24 than afterward, Walleye larvae encountered warm temperatures and low flows, and survival to the Maple Island Road site was fivefold higher before April 24 than afterward or during 2009. Due to the favorable environmental conditions early in 2010, the estimate of annual larval Walleye production downstream was sevenfold higher in 2010 than in 2009. The temporal differences in larval survival during 2010 also may have been caused by predation. Although White Perch and White Bass do not migrate into the lower Muskegon River during the spring, several other potential predators of Walleye larvae inhabit the lower Muskegon River, including sunfishes (Centrarchidae) and shiners (Cyprinidae; O'Neal 1997).

Although not a direct focus of this study, differences observed in the size of Walleye spawners and larvae over the spawning and hatching periods suggested that maternal characteristics potentially influenced Walleye reproductive success. Such influences can occur if the condition or size of spawning females or their offspring varies among years or during the spawning season (Madenjian et al. 1996; Secor 2000; Johnston et al. 2007; Venturelli et al. 2010; Wang et al. 2012). Larger females in better spawning condition may produce larger eggs, resulting in larger larvae at hatch (Johnston and Leggett 2002; Wang et al. 2012), which may have better survival and feeding success in prey-limited environments (Venturelli et al. 2010). In our study, the average TL of newly hatched Walleye larvae increased as temperatures warmed, but there was no relationship between larval length and survival. Although females that spawned during the first week of the season were larger than females that spawned later, eggs that were measured from large and small females did not differ in size between 2009 and 2010 (Z. Feiner, Purdue University, personal communication), and Walleye larvae that hatched earlier-and likely hatched from the eggs of larger females-were smaller than the larvae that hatched later. Likewise, in a study of the Saginaw River by Jude (1992), Walleye larvae that hatched early in the spawning season were smaller than those that hatched later. However, although early hatching Walleye larvae were smaller, they may have been in better condition than laterhatching larvae. We did not measure the condition of Walleye larvae, but we did note that the early hatching larvae tended to have larger yolk sacs than later-hatching individuals. In laboratory studies of Yellow Perch Perca flavescens, Heyer et al. (2001) and Andree et al. (2015) observed that the larval progeny of large females had larger yolk sacs but smaller sizes at hatch than the progeny of small females. Andree et al. (2015) noted that the survival of newly hatched Yellow Perch larvae $(<5 \mathrm{~d}$ posthatch [dph]) had a strong negative relationship to female size and age, whereas the survival of older larvae ( $>9 \mathrm{dph})$ was unrelated to maternal traits. Those authors speculated that selective forces could vary for different sizes and ages of 
Yellow Perch larvae; newly hatched larvae may require a large yolk investment to survive in the more prey-limited environments encountered early during development, while selective pressures on older larvae may favor attributes associated with larger size and growth rate as temperatures warm and as predation pressures increase.

Environmental variability also may affect maternal influence on Walleye larvae. Variability in river hydrology was negatively correlated with egg size among populations of the Southern Pygmy Perch Nannoperca australis (Morrongiello et al. 2012). Interannual variation in maternal effects on egg size may differ within and among Walleye populations (Feiner, personal communication). These experimental and empirical results may explain the observed temporal trend of small Walleye larvae hatching in cold temperatures during the early portion of the spawning season in the Muskegon River.

Results of our study on the density and survival of Walleye eggs and larvae support earlier evidence (Day 1991; Mion et al. 1998; Ivan et al. 2010; DuFour et al. 2014) suggesting that abiotic factors can regulate the production of Walleye early life stages in the Muskegon River and other Great Lakes tributaries. In particular, strong and variable river discharge and/or cold temperatures during Walleye egg incubation and larval hatch may lower egg survival and larval production. We believe that future research should focus on both biotic and abiotic factors influencing the survival and growth of Walleye larvae in the Muskegon River, Muskegon Lake, and other Great Lakes nursery habitats. Abiotic environmental factors are predicted to change under climate warming scenarios that are forecast for the Muskegon River by 2070 (Wiley et al. 2010); river water temperature is predicted to increase by $3-5^{\circ} \mathrm{C}$, and discharge is also expected to increase. It is unclear whether the benefit of increased temperatures will counteract the negative influence of predicted higher discharge on the survival of Walleye eggs and larvae. We suspect that Alewives and other planktivorous fishes (e.g., White Perch) also may limit Walleye recruitment through predation on the larvae as they drift from the Muskegon River to Muskegon Lake. Events in Lake Huron suggest that the dramatic decline in adult Alewives-known predators of fish larvae-has removed the reproduction and recruitment bottlenecks that had existed for Walleyes and other nearshore native species (e.g., Fielder et al. 2007; Schaeffer et al. 2008).

\section{ACKNOWLEDGMENTS}

Funding for this study was provided by the Michigan Habitat Improvement Fund and the Great Lakes Fishery Trust. We received field support from the MDNR Institute for Fisheries Research (IFR); the School of Natural Resources and Environment, University of Michigan; the National Oceanic and Atmospheric Administration (NOAA),
Great Lakes Environmental Research Laboratory (GLERL); and the Annis Water Resources Institute, Grand Valley State University. Danielle Forsyth (MDNR-IFR), Lacey Mason (MDNR-IFR), and Cathy Darnell (NOAA-GLERL) provided assistance with graphics. This is Contribution 1750 from the NOAA-GLERL.

\section{REFERENCES}

Anderson, R. M., B. F. Hobbs, and J. F. Koonce. 2006. Modeling effects of forest cover reduction on larval Walleye survival in Lake Erie tributary spawning basins. Ecosystems 9:725-739.

Andree, S. R., Z. S. Feiner, J. W. Bledsoe, A. M. Cragun, and T. O. Höök. 2015. Ontogenetic variability of maternal effects in an iteroparous fish. Ecology of Freshwater Fish 24:384-396.

Auer, N. A., editor. 1982. Identification of larval fish of the Great Lakes basin with emphasis on the Lake Michigan drainage. Great Lakes Fishery Commission, Special Publication 82-3, Ann Arbor, Michigan.

Colby, P. J., R. E. McNicol, and R. A. Ryder. 1979. Synopsis of biological data on the Walleye. Food and Agriculture Organization of the United Nations, Fisheries Symposium 119, Rome.

Corbett, B. W., and P. M. Fowles. 1986. Spawning and larva drift of sympatric Walleyes and White Suckers in an Ontario stream. Transactions of the American Fisheries Society 115:41-46.

Crane, D. P., and J. M. Farrell. 2013. Spawning substrate size, shape, and siltation influence Walleye egg retention. North American Journal of Fisheries Management 33:329-337.

Cressie, N., C. A. Calder, J. S. Clark, J. M. Verhoef, and C. K. Wilkie. 2009. Accounting for uncertainty in ecological analysis: the strengths and limitations of hierarchical modeling. Ecological Applications 19:553-570.

D'Amours, J. D., S. Thibodeau, and R. Fortin. 2001. Comparison of Lake Sturgeon (Acipenser fulvescens), Stizostedion spp., Catostomus spp., Moxostoma spp., Quillback (Carpiodes cyprinus), and Mooneye (Hiodon tergisus) larval drift in Des Prairies River, Quebec. Canadian Journal of Zoology 79:1472-1489.

Day, R. M. 1991. Population dynamics and early life history of Muskegon River Walleyes. Master's thesis. Michigan State University, East Lansing.

DuFour, M. R., J. J. Pritt, C. M. Mayer, C. A. Stow, and S. S. Quian. 2014. Bayesian hierarchical modeling of larval Walleye (Sander vitreus) abundance and mortality: accounting for spatial and temporal variability on a large river. Journal of Great Lakes Research 40(Supplement 3):29-40.

Fielder, D. G., J. S. Schaeffer, and M. V. Thomas. 2007. Environmental and ecological conditions surrounding the production of large year-classes of Walleye (Sander vitreus) in Saginaw Bay, Lake Huron. Journal of Great Lakes Research 33(Supplement 1):118-132.

Gelman, A., J. B. Carlin, H. S. Stern, D. B. Dunson, A. Vehtari, and D. B. Rubin 2014. Bayesian data analysis, 3rd edition. CRC Press, Boca Raton, Florida.

Gelman, A., and J. Hill. 2007. Data analysis using regression and multilevel/ hierarchical models. Cambridge University Press, New York.

Giuliano, A. M. 2011. Effects of zebra mussel invasion on juvenile steelhead distribution, diet, growth, and condition in the Muskegon River, Michigan. Master's thesis. University of Michigan, Ann Arbor.

Hanchin, P. A., R. P. O’Neal, R. D. Clark Jr., and R. N. Lockwood. 2007. The Walleye population and fishery of the Muskegon Lake system, Muskegon and Newaygo counties, Michigan, in 2002. Michigan Department of Natural Resources, Fisheries Special Report 40, Ann Arbor.

Harvey, A. C., and C. Fernandes. 1989. Time series models for count or qualitative observations. Journal of Business and Economic Statistics 7:407-417.

Heidinger, R. C., R. C. Brooks, D. Leitner, and I. Soderstrom. 1997. Prediction of Walleye egg and embryo survival at two stages of development. Progressive Fish-Culturist 59:64-67. 
Heyer, C. J., T. J. Miller, F. P. Binkowski, E. M. Caldarone, and J. A. Rice. 2001. Maternal effects as a recruitment mechanism in Lake Michigan Yellow Perch (Perca flavescens). Canadian Journal of Fisheries and Aquatic Sciences 58:1477-1487.

Ivan, L. N., E. S. Rutherford, J. A. Tyler, and C. M. Riseng. 2010. Density, production and survival of Walleye eggs (Sander vitreus) in the Muskegon River, Michigan. Journal of Great Lakes Research 36:328-337.

Johnson, F. 1961. Walleye egg survival during incubation on several types of bottom in Lake Winnibigoshish, Minnesota, and connecting waters. Transactions of the American Fisheries Society 90:312-322.

Johnston, T. A., and W. C. Leggett. 2002. Maternal and environmental gradients in the egg size of an iteroparous fish. Ecology 83:1777-1791.

Johnston, T. A., M. D. Wiegand, W. C. Leggett, R. J. Pronyk, S. D. Dyal, K. E. Watchorn, S. Kollar, and J. M. Casselman. 2007. Hatching success of Walleye embryos in relation to maternal and ova characteristics. Ecology of Freshwater Fish 16:295-306.

Jones, M. L., J. K. Netto, J. D. Stockwell, and J. B. Mion. 2003. Does the value of newly accessible spawning habitat for Walleye (Stizostedion vitreum) depend on its location relative to nursery habitats? Canadian Journal of Fisheries and Aquatic Sciences 60:1527-1538.

Jude, D. J. 1992. Evidence for natural reproduction by stocked Walleyes in the Saginaw River tributary system, Michigan. North American Journal of Fisheries Management 12:386-395.

Koenst, W. M., and L. L. Smith Jr. 1976. Thermal requirements of the early life history stages of Walleye, Stizostedion vitreum vitreum, and Sauger, Stizostedion canadense. Journal of the Fisheries Research Board of Canada 33:1130-1138.

Latif, M. A., R. A. Bodaly, T. A. Johnston, and R. J. P. Fudge. 1999. Critical stages in developing Walleyes. North American Journal of Aquaculture 61:34-37.

Lechner, A., H. Keckeis, E. Schludermann, P. Humphries, N. McCasker, and M. Tritthart. 2014. Hydraulic forces impact larval fish drift in the freeflowing section of a large European river. Ecohydrology 7:648-658

Lunn, D. J., D. Spiegelhalter, A. Thomas, and N. Best. 2009. The BUGS project: evaluation, critique and future directions. Statistics in Medicine 28:3049-3067.

Madenjian, C. P., R. O'Gorman, D. B. Bunnell, R. L. Argyle, E. F. Roseman, D. M. Warner, J. D. Stockwell, and M. A. Stapanian. 2008. Adverse effects of Alewives on Laurentian Great Lakes fish communities. North American Journal of Fisheries Management 28:263-282.

Madenjian, C. P., J. T. Tyson, R. L. Knight, M. W. Kershner, and M. J. Hansen. 1996. First-year growth, recruitment and maturity of Walleyes in Lake Erie. Transactions of the American Fisheries Society 125:821-830.

Manny, B. A., D. J. Jude, and R. L. Eshenroder. 1989. Field test of a bioassay procedure for assessing habitat quality on fish spawning grounds. Transactions of the American Fisheries Society 118:175-182.

Manny, B. A., G. W. Kennedy, J. D. Allan, and J. R. P. French. 2007. First evidence of egg deposition by Walleye (Sander vitreus) in the Detroit River. Journal of Great Lakes Research 33:512-516.

Mion, J., R. A. Stein, and E. A. Marschall. 1998. River discharge drives survival of larval Walleye. Ecological Applications 8:88-103.

Morrongiello, J. R., N. R. Bond, D. A. Cook, and B. B. A. Wong. 2012. Spatial variation in egg size and egg number reflects trade-offs and bethedging in a freshwater fish. Journal of Animal Ecology 81:806-817.

O’Neal, R. P. 1997. The Muskegon River watershed assessment. Michigan Department of Natural Resources, Fisheries Division, Fisheries Special Report 19, Ann Arbor.

Pavlov, D. S., V. N. Mikheev, A. I. Lupandin, and M. A. Skorobogatov. 2008. Ecological and behavioural influences on juvenile fish migrations in regulated rivers: a review of experimental and field studies. Hydrobiologia 609:125-138.

Priegel, G. R. 1970. Reproduction and early life history of the Walleye in the Lake Winnebago region. Wisconsin Department of Natural Resources Technical Bulletin 45.

Pritt, J. J., M. R. DuFour, C. M. Mayer, P. M. Kocovsky, J. T. Tyson, E. J. Weimer, and C. S. Vandergoot. 2013. Including independent estimates and uncertainty to quantify total abundance of fish migrating in a large river system: Walleye (Sander vitreus) in the Maumee River, Ohio. Canadian Journal of Fisheries and Aquatic Sciences 70:803-814.

Qian, S., and Z. Shen. 2007. Ecological applications of multilevel analysis of variance. Ecology 88:2489-2495.

Quist, M. C., C. S. Guy, R. J. Bernot, and J. L. Stephen. 2004. Factors related to growth and survival of larval Walleyes: implications for recruitment in a southern Great Plains reservoir. Fisheries Research 67:215-225.

Raabe, J. K., and M. A. Bozek. 2015. Influence of wind, wave, and water level dynamics on Walleye eggs in a north temperate lake. Canadian Journal of Fisheries and Aquatic Sciences 72:570-581.

Roseman, E. F., W. W. Taylor, D. B. Hayes, R. C. Haas, R. L. Knight, and K. O. Paxton. 1996. Walleye egg deposition and survival on reefs in western Lake Erie (USA). Annales Zoologici Fennici 33:341-351.

Roseman, E. F., W. W. Taylor, D. B. Hayes, A. L. Jones, and J. T. Francis. 2006. Predation on Walleye eggs by fish on reefs in western Lake Erie. Journal of Great Lakes Research 32:415-423.

Ruetz, C. R. III, and C. A. Jennings. 2000. Swimming performance of larval Robust Redhorse Moxostoma robustum and low-velocity habitat modeling in the Oconee River, Georgia. Transactions of the American Fisheries Society 129:398-407.

Schaeffer, J. S., D. M. Warner, and T. P. O'Brien. 2008. Resurgence of Emerald Shiner Notropis atherinoides in Lake Huron's main basin. Journal of Great Lakes Research 34:395-403.

Schneider, J. C., J. Copeland, and M. Wolgamood. 2002. Tolerance of incubating Walleye eggs to temperature fluctuations. North American Journal of Aquaculture 64:75-78.

Schneider, J. C., and J. H. Leach. 1979. Walleye stocks in the Great Lakes, 1800-1975: fluctuations and possible causes. Great Lakes Fishery Commission Technical Report 31.

Schneider, J. C., T. J. Lychwick, E. J. Trimberger, J. H. Peterson, R. O’Neal, and P. J. Schneeberger. 1991. Walleye rehabilitation in Lake Michigan, 1969-1989. Pages 23-62 in P. J. Colby, C. A. Lewis, and R. L. Eshenroder, editors. Status of Walleye in the Great Lakes: case studies prepared for the 1989 workshop. Great Lakes Fishery Commission, Special Publication 91-1, Ann Arbor, Michigan.

Secor, D. H. 2000. Spawning in the nick of time? Effect of adult demographics on spawning behaviour and recruitment in Chesapeake Bay Striped Bass. ICES Journal of Marine Science 57:403-411.

Steinman, A. D., M. Ogdahl, R. Rediske, C. R. Ruetz III, B. A. Biddanda, and L. Nemeth. 2008. Current status and trends in Muskegon Lake, Michigan. Journal of Great Lakes Research 34:169-188.

Sturtz, S., U. Ligges, and A. Gelman 2005. R2WinBUGS: a package for running WinBUGS from R. Journal of Statistical Software [online serial] 12(3).

USGS (U.S. Geological Survey). 2011. USGS: water data for the nation (National Water Information System). Available: http://waterdata.usgs. gov/nwis. (October 2011).

Venturelli, P. A., C. A. Murphy, B. J. Shuter, T. A. Johnston, P. J. van Coeverden de Groot, P. T. Boag, J. M. Casselman, R. Montgomerie, M. D. Wiegand, and W. C. Leggett. 2010. Maternal influences on population dynamics: evidence from an exploited freshwater fish. Ecology 91:2003-2012.

Wang, H.-Y., D. W. Einhouse, D. G. Fielder, L. G. Rudstam, C. S. Vandergoot, A. J. VanDeValk, T. G. Zorn, and T. O. Höök. 2012. Maternal and stock effects on egg size variation among Walleye Sander vitreus stocks from the Great Lakes region. Journal of Great Lakes Research 38:477-489.

Wiley, M. J., D. W. Hyndman, B. C. Pijanowski, A. D. Kendall, C. Riseng, E. S. Rutherford, S. T. Cheng, M. L. Carlson, J. A. Tyler, R. J. Stevenson, P. J. Steen, P. L. Richards, P. W. Seelbach, J. M. Koches, and R. R. Rediske. 2010. A multi-modeling approach to evaluating climate and land use change impacts in a Great Lakes river basin. Hydrobiologia 657:243-262.

Wolter, C., and A. Sukhodolov. 2008. Random displacement versus habitat choice of fish larvae in rivers. River Research and Applications 24:661-672. 